\title{
Using Secondary Analysis to Maintain a Critically Reflexive Approach to Qualitative Research
}

\begin{abstract}
Maintaining a 'critical reflexivity' (Heaphy 2008) or 'investigative epistemology' (Mason 2007 ) in relation to the sedimented assumptions built up over the course of one's own research history and embedded in common research boundaries, is difficult. The type of secondary analysis discussed in this paper is not an easy or quick 'fix' to the important issue of how such assumptions can embed themselves over time in methods chosen and questions asked. Even though archived studies are often accompanied by relatively detailed metadata, finding relevant data and getting a grasp on a sample, is timeconsuming. However, it is argued that close examination of rawer data than those presented in research reports from carefully chosen studies combining similar foci and epistemological approaches but with differently situated samples, can help. Here, this process highlighted assumptions underlying the habitual disciplinary locations and constructions of so-called 'vulnerable' as opposed to 'ordinary' samples, leading the author to scrutinise aspects of her previous research work in this light and providing important insights for the development of further projects.
\end{abstract}

\section{Keywords \\ Qualitative secondary analysis (QSA), reflexive sociology, sedimented assumptions, research boundaries, sample characterisation, space, objects}

A great advantage of qualitative data is its 'capacity to cope with and make sociological sense of ambiguity, messiness and ordinary complexities' (Mason 2007: 2.1). Mason emphasises that an 'investigative epistemology' (2007) is required in relation to the identification and interpretation of any qualitative data. Further, Heaphy uses the term 'reflexive sociology' in arguing that researchers should employ an 'ethic of critical reflection and an openness and willingness to subject assumptions, procedures and narratives to intense scrutiny' (2008: 5.3). He also highlights the broadly political significance of (not) engaging in such scrutiny and the need to 'develop alternative research and sociological strategies that would incorporate awareness of knowledge production as political practice' (2008: 4.3). This paper argues that secondary analysis of others' data - as opposed to a reliance on 'tidied' research reports and journal articlesprovides one fruitful, if demanding, tool to subject one's own research practice to such examination.

The paper reflects on the author's qualitative secondary analysis (QSA) of data from the qualitative, longitudinal Timescapes 'Siblings and Families' ('SAF') study, ', which includes three waves of interviews with young people from mixed, but predominantly 'ordinary', backgrounds across Britain. The aim was to interrogate sedimented assumptions built up over the course of her previous research work with participants from predominantly 'vulnerable' backgrounds, while developing a new project concerned with belonging and space with a similarly vulnerable sample. Identifying a project combining sufficient 'proximity' as to substantive interests, methods and epistemology to the new project, with sufficient 'distance' as to sample characteristics from her previous work, was difficult. Further, once identified, the meta- and individual interview data provided proved no substitute for reading through large quantities of data. However, this process forced the author to think carefully about her own research practice. It highlighted how unexamined and unnuanced assumptions of difference in relation to 'ordinary' or 'vulnerable' samples, 
and the often different disciplinary location of research with each, may affect the data produced in terms of methods chosen, questions (not) asked and interpretations made, potentially reinforcing the contemporary pathologisation of more vulnerable groups.

The first two sections of this paper will examine the need for such self-scrutiny, first in theoretical terms and then in relation to the author's own research history. The main body of the paper will then discuss the QSA undertaken to illustrate both the difficulties and significant benefits of this process.

\section{Theoretical Background: QSA and reflexivity}

Much initial concern in relation to qualitative secondary analysis, and the requirement placed on all ESRC-funded UK researchers to archive their dataii, focused on subsequent analysts' epistemological 'distance' from the original context in which data are produced. Mauthner et al. argue that 'the particulars of the initial research engagement are inaccessible to subsequent users, and this in itself delimits the possibilities for valid substantive findings' (1998). These authors therefore privilege a notion of 'reflexivity' related to the particular intersection between the original researchers and the data produced. For Geiger et al. however, such an argument:

can collapse into the inference that only the 'original' researcher who carried out the interview has access to the true meaning of the encounter and even its traces in the transcript (2010: 8).

Irwin and Winterton further argue that '[p]resence at the point of data generation is not a final arbiter' (2012: 5.1). Similarly, Mason warns against taking 'being there' as a means to claim privileged insight, and emphasises that Mauthner et al.'s approach places 'enormous epistemological weight onto the notion of 'successful reflexivity' (2007: 3.23.3). In contrast, Mason argues for 'the epistemological value in allowing for a range of reflexive interpretations of data, some from close range and some from a distance' (2007: 3.3).

These debates have contributed to a broader discussion of the scope and purposes of methodological reflexivity. Notably, Mason describes Mauthner et al.'s approach as 'antihistorical' (2007: 3.3). In relation to research more generally, Burawoy (2009) also argues that an individualised notion of reflexivity should not cut researchers off from consideration of the history of their particular discipline and of the influence of its theoretical developments on their research practice. He highlights the need to 'recognise how theoretically embedded we are when we enter the field' and how the data produced will be influenced by starting assumptions (2009:8). As such, he emphasises the importance for researchers of reflecting on the ways their own research histories are constructed through the historical and momentary concerns of the disciplines in which they work, and how these might affect methods chosen, questions asked and the interpretation of data in each particular project.

One example of such reflection is provided by Irwin et al.'s account of cross-project Timescapes meetings at which researchers noted 'alternative conceptualisations' (2012: 68) of their data, as well as 'hearing silences' (2012: 73) therein (also see Winterton et al. 2011). The processes by which these alternative conceptualisations were arrived at, and silences heard, are not described in detail in their paper. One example given was the reluctance of one project's female researchers to ask much older interviewees (aged over 75) about their pre-marital sexual experiences, unlike those in a project interviewing younger men. This absence suggests the influence on the data collected of perceptions 
of 'appropriate' questioning in inter-generational interviews and potentially of researchers' disciplinary histories. It also highlights the ways in which:

[p]articular conceptions of the nature of the social phenomena and of salient contextual information are embedded in methodological decisions and data collection strategies, and will shape the available data and encourage particular 'readings' of the social phenomena being researched (Irwin \& Winterton 2012: 3.6).

In addition, Heaphy's (2008) advocacy of a 'radical reflexivity' emphasises the way that knowledge claims, including those of sociologists, are caught up in the flow of power and history, 'focusing on some realities and editing out others' with political consequences. Drawing on Bourdieu, he notably criticises the way that sociological narratives of gay and lesbian lives have emphasised a narrative of sameness, while neglecting dynamics of 'power and difference' between members of these groups. To counter, he recommends a 'reconstructionist' 'ethic of critical reflection and an openness and willingness to subject our assumptions, procedures and narratives to intense scrutiny', 'making visible as far as possible the dynamics, assumptions and experiences that shape social knowledge' (2008: 5.3).

The following section will explore the author's decision to engage in QSA as a potential means of interrogating sedimented and unexamined 'starting' assumptions developed over the course of her research history.

\section{The author's route to QSA as a reflexive tool}

Like many qualitative research histories, the author's is characterised by small-scale and often similar samples, influenced in part by funders' and grantholders' perceptions of research expertise, and funders' specifications for grants and relevant sample groups, further compounded by ethics committees' constructions of the same. In her case, much of this work has been with children and young people characterised as 'vulnerable'. In recent years, such work has often been pursued in applied contexts drawing on social work and psychological rather than sociological concerns and theories. More sociological work, in contrast, has tended to focus on children and young people from 'ordinary' families (Gillies 2000; Wilson 2013).

The researcher's awareness of these research boundaries and interest in QSA grew out of re-interrogating data from two previous projects exploring young people's experience of parental substance misuse (PSM) problems (Bancroft et al. 2004; Houmøller et al. 2011). In both projects, the samples were predominantly composed of young people from relatively difficult socio-economic and relational circumstances, rather than more 'ordinary' (or as Mason and Tipper put it 'ordinarily complex' (2010)) backgrounds. Overlaps between 'ordinary' and more difficult samples are inevitable (Gillies 2000). However, re-reading the PSM data suggested ways in which such initial characterisations of the samples as vulnerable, and the more 'applied' contexts of these projects had influenced the different questions asked and the data and evidence produced (Wilson 2013).

In the first of these projects, particular attention was paid to identifying the levels of PSM experienced, and to identifying 'abuse' according to institutional definitions. The second focused more on family interactions from multiple perspectives and employed more 
interactive methods. In both cases however, the focus was greatly influenced by funders' 'policy-relevant' concerns. Re-reading this data in the light of the growing sociological interest in the sensory and material (DeNora 2000; Pink 2009; Miller 2010; Mason \& Davies 2010) led to the realisation that many respondents had expressed their experience of PSM in sensory terms. For example, they spoke about unwanted noise at times and in spaces conventionally associated with quiet, and how they had often used music to blank out such sounds and create a 'warmer' environment in bedrooms (Wilson et al. 2012). This work led to the 'Sights and Sounds' or 'SAS' projectiii proposal to employ visual and audial methods to explore the lived experience (whether positive, negative or ambivalent) of belonging in domestic spaces of 'looked after'iv young people (a group often characterised as 'vulnerable'). Chastened by the feeling that the PSM respondents had not been listened to carefully enough, the author incorporated an element of QSA into the initial 'concept-building' period of the SAS grant.

The QSA discussed here then, is not the systematic re-interpretation of substantive data envisaged by Mauthner et al., nor a historical re-study focused on changes and continuities in a community over time (Crow 2012). Instead, the idea was to get 'closer' to other researchers' conceptual and methodological approaches, and to the interrelationships and interactions between these, than is often possible in polished journal articles. I wanted to learn from other researchers' conceptualisations of domestic spaces and the methods they had used to explore young people's understandings of them. Further, I hoped that exploring data from projects exploring similar issues, but with a different (more 'ordinary') sample would help to reflect on and better situate previous work that had influenced the SAS proposal. Notably, I was concerned to examine how the characterisations of research samples in different disciplinary and funding contexts might have influenced the data and evidence produced, and might serve to correct or nuance mis- or over- interpretations of practices primarily or exclusively in terms of the difficult family and socio-economic circumstances of the sample. In particular, in the current political climate, I was concerned that such interpretations might lead to the further pathologisation of apparent differences between more marginalised groups of young people and those characterised as 'ordinary' (and often tacitly understood as 'normal').

\section{Difficulties associated with the QSA undertaken}

The process of identifying secondary data with a sufficient degree of 'fit' with my aims in developing the SAS project-that is a sufficient degree of 'distance' from the sample groups of previous projects and 'proximity' in substantive and epistemological terms was difficult. Despite reading advice (Irwin \& Winterton 2011), getting a sufficient sense of projects on the basis of the keywords and sample meta-data often provided, was not an easy process. Studies would seem relevant from the information provided in that they indicated a concern with young people, transitions or domestic spaces but the only way to get an adequate 'feel' for each project was to read through a sufficient amount of its data. This was a time-consuming process, which often led to a conclusion that a perused project did not feel 'right' methodologically or epistemologically. As a result, the initial strategy of reviewing data from several projects with keywords relevant to my proposed project proved misguided, even in the privileged context of a research project with a funded period for conceptual development. 
Ultimately, after reading through data from several projects, finding the SAF project relatively early on in this process was partly serendipitous. Although it, like others in the Timescape archive, had been identified as potentially (although not immediately) relevant on the basis of keywords and descriptions, it had not reached the top of this list when the author was introduced to material from SAF at a practical Timescapes workshop. This brief encounter confirmed that this project involved participants from predominantly 'ordinary' backgrounds and included questions and employed photo-elicitation in relation to domestic, favourite and ideal places. At this initial point therefore, it seemed that there was a degree of both substantive (young people, domestic space) and methodological (photo elicitation) 'fit'. More importantly though, reading through transcripts and examining related photos highlighted this 'fit' in more epistemological, and ultimately somewhat subjective, terms. This data had a more ethnographic and sensory and textured 'feel', in contrast to which interviews from other perused projects seemed somehow 'flat'. Further confirmation of a similarity in epistemological approach between the SAF and SAS projects came through the SAF project guide (Weller \& Edwards 2011) (not then available online). One of the lead SAF researchers generously provided this document, and answered further questions around the team's approach and the treatment of some 'sensitive' data excluded from the archive.

A further difficulty, even after the SAF project had been identified however, was gaining a detailed sense of the relevant elements of the complex data set archived. The SAF study invited 50 participants aged 5-13 at the time of their original interviews in three previous projects to take part in two waves of follow up work, the first of which focused on sibling relationships and the second on locality, transitions to secondary school and social capital. The archived data therefore includes up to three interview transcripts with each participant. Other data encompasses photographs of domestic spaces (in wave 3), as well as relational maps, questionnaires, essays on future aspirations, vignettes and timelines. Having read through examples of each type of data, I decided to focus my analysis on the three waves of interviews, the researchers' fieldnotes and the photographs mentioned above.

Gaining a sense of the social circumstances of each interviewee also took time in that, perhaps for ethical reasons, the data provided on each interview coversheet is not tabulated either in the archive or the project guide. Further, and as also noted by Baker (2010), this information (respondent's age, gender, marital status, occupation, location, educational qualifications, ethnicity) was not sufficient to situate the interviewees' circumstances adequately for the author's purposes of comparing an 'ordinary' with the 'vulnerable' samples characteristic of her previous work. Only by reading through each available transcript could key indicators of social circumstances be gleaned, such as types of school attended, parental occupations, and the type and tenure of housing lived in, and, importantly, of changes in these across each interview sweep. Once again there seemed to be few 'short cuts' in spite of the emphasis in the archives on providing key words and other data to facilitate such tasks.

The time required for engaging in such analysis should not be under-estimated therefore. There were however numerous benefits to this process, as described in the following sections.

The advantages of the QSA undertaken

Identifying silences and assumptions related to particular samples 
As discussed, one of the purposes of undertaking the QSA of data described in this paper was to compare substantive and methodological approaches to, and implicit conceptualisations of, a relatively 'ordinary sample' with those produced in previous work with relatively 'vulnerable' samples. This analysis reinforced certain perceptions but also suggested revealing, and sometimes uncomfortable, 'silences' and unexamined assumptions in this previous work.

Reading through the SAF interview transcripts suggested that several participants lived affluent and privileged lives. However, some had experienced more difficult circumstances including poverty, living in rundown flats and areas, parental mental and physical ill-health, difficult family reconstitutions and frequent house moves. Elements of these interviews recalled those of many PSM participants. For example, a few respondents spoke in sensory terms of disliking where they lived:

I don't really like this house ... I think it's too small and don't like the decoration ... it's horrible (Lizzie at 15).

Annev, who attended breakfast club at her school at 11, was in trouble with the police at 15 and who had run away from home several times by 17, was 'embarrassed' by where she lived and wished that Child Benefit could be increased so that her house could be 'fixed up' more. She had a keen sense then of where the money in her household came from and of disadvantage as a result of living in a council house in a deprived, urban area:

Oh my gosh! It will be a lot easier for her (niece) cos my sister has got a house and she lives in a nice area but with me I lived in a council house and it wasn't such a nice area... someone got shot down [the local street] the other day.

In Anne and other respondents' cases, less privileged home circumstances were further indicated in the texture of their photographs which suggested few possessions, poor quality furniture, and rooms requiring paint and possibly better insulation or heating.

The issue of poverty was not probed however, and in the SAF data generally, discussion of other 'difficult' issues, including violence and family conflict, were de-limited. The SAF data contains striking accounts of the effects of street violence on the lives of inner city, particularly London, respondents. DJ Kizzel (at 14) recounted having been shot in the neck with a BB gun; Jay's brother had been severely beaten up. In her first interview, Alannah spoke of an acquaintance who was in a coma as a result of a stabbing. In her second interview at 18 , she explained:

If I go to [inner-city areavi] it's if I'm just going to pick up something quickly from a shop... or whatever and only during the day.

At 13, Louise was also very conscious of the need to avoid certain areas:

I have to get off the bus right outside there [a 'rough' estate]. That's why I don't come home late. Because I always think there might be someone there...Or I get off in [local street], where [friend] gets off, and then I walk up.

Respondents living close to such areas distanced themselves narratively from reports of violence in several ways; young women emphasised that it only happened to boys, some implied that the person attacked deserved it, or that they themselves were protected as 
they knew the people and bus routes in their area. Such distancing was more difficult for more working class respondents (Anne, Allie, Lizzie, Jazzy, Louise), however, in whose accounts the violence seemed 'closer', and a sense of perceived threat seemed to grow over the course of their interviews. At 19, Louise was no longer so sure that she could avoid trouble:

In [local shopping centre] someone got stabbed...it's only like five minutes away from my house and that's not even anyone who's done anything wrong...that could be me for looking at someone wrong.

It was noticeable that these accounts were produced in response to questions that located safety concerns outside rather than inside the home. Respondents were asked questions such as 'Are there any areas that you don't feel particularly safe (or comfortable) in?' The use of the word 'area' rather than 'place' and the location of these questions among others relating to the surrounding area may have discouraged consideration of whether or not the respondents felt safe in their homes. The SAF project was of course particularly focused on intra-generational relationships, and, as will be discussed, did analyse sibling conflict. However, certain episodes that might have hinted at more difficult family circumstances remained unprobed.

Richard, a relatively privileged young man, related:

RICHARD: I ran away from home a year and a half ago.

INT: Did you?

RICHARD: $\quad$ I ended up staying at my grandma's house ... for a couple of months, ...and it was me being not having to do chores and being nagged and me coping with buying food and doing whatever I want ...

After this exchange, the interview moved on, perhaps because the interviewer felt under time pressure to cover questions related to the core purpose of the project, or perhaps they judged that 'running away' was an overly dramatic label for this event. Reading through Allie's interviews however led to a cumulative sense of recognition of a home environment similar to that of many of the PSM respondents. The poverty of her home circumstances was suggested by her photos, but Allie also related how she found it difficult to be with the rest of her family especially her mother, spent most of her time in her room, did not often bring friends to her 'embarrassing' home and preferred to stay out of the house 'Most of the time yeah because I don't like being here ...'

A secondary analyst cannot know the answer to why certain issues were not probed further. Given the stated focus of the study, it may be that the researcher felt that consent had not been given to discuss parental relationships, or that pursuing such issues might have caused distress. Indeed the project guide points to some respondents' disarray on receipt of a Childline leaflet (Weller \& Edwards 2011: 27). However, in a study with a 'vulnerable' sample, a researcher would have felt under great pressure to explore such accounts further, having previously discussed such issues at length with ethics committees and agencies working with the participants. Such observations also raise the problem identified by Gillies (2000) that often more isolated difficult accounts within 'ordinary' samples are not written up and, as such, the complexity and pain within 'ordinary' families may be under-estimated.

Similarly, re-reading previous work in the light of the SAF data raised difficult questions in relation to the PSM projects. For example, the relative directness of some questioning 
used with respect to some potentially very sensitive issues, including whether or not parents had been violent or otherwise abusive, was troubling and avoided in the SAS study. The SAF analysis also suggested some important omissions in the PSM work, and in particular, the importance of homework and extra-curricular activities in the respondents' lives. Most SAF respondents emphasised how much time they spent on such activities, encouraged by parents and helped by or helping siblings and friends, often employing a language reminiscent of paid work in these accounts:

Monday I do piano; Tuesday I do tennis and swimming; Wednesday I do swimming; Thursday I do tennis and Friday is my day off (Carl at 12).

IZZY: I have quite a busy week actually because on Tuesday I have band practice at six. On Wednesday I teach a ballet class for Grade 1, ...and me and [friend] are doing it for a Duke of Edinburgh Award for like voluntary work. On Thursday I have I have Woks which is the singing-choir thing at my school and then [YAP?] and then I have dance.

INT: What's YAP?

IZZY: $\quad$ A Drama class. Woks is from 3.30 to normally 4.30 and Yap is from 5.00 to 6.00 and my dance is 6.15 to 7.30 , which is like always really stressful and I have no time at all. On Friday I just go out (at 14).

As with parental relationships in the SAF study, these activities were not the major theme of the PSM projects, and the interviews were sometimes constrained by time commitments. Further, favourite activities, qualifications and future aspirations were addressed, often leading to discussions of activities of which respondents were proud. However, it is possible that unexamined assumptions as to the participants' likely educational trajectory might have influenced this omission. Further, it may be that through such omissions, this absence might have contributed, however unintentionally, to a sense that education is less important to, or less worthy of study with, young people from difficult family backgrounds. Similarly, the inclusion of more questions relating to the young people's own drug use than to their education in one of these projects suggests a failure to stand back sufficiently from the funders' risk-focused agenda. This process of secondary analysis therefore suggested the importance to data production of initial conceptualisations of research samples, by funders, ethics committees and (different) researchers, as well as the potential 'political' consequences of these in terms of reproducing stereotyped perceptions of certain groups (Heaphy 2008).

Interrogating and developing key conceptions

Analysing the SAF data also helped to confirm the relevance of, but also to interrogate and develop a more nuanced approach to central substantive concerns of the developing SAS project, including the researchers' conceptualisations of belonging, and of 'home' spaces.

First, this analysis confirmed the importance accorded to noise in constructing normative understandings of both places and family life, identified in the PSM work (Wilson et al. 2012). A certain amount of noise was viewed as intrinsic to family:

I don't think I'd like to come home to NO noise ... obviously I do when I come home late but it's nice to just sit down in the front room and watch 'Big Brother' with everyone (Alannah at 17).

However, here too, it was important that these noise levels were controlled. The most common response to a general question, 'What about any rules around the house?', 
asked in the first wave of SAF projects, highlighted how rules on making noise were perceived as critical to trying to live together and with neighbours:

If you can hear my music outside my bedroom then it's too loud (Anne at 11).

You take your shoes off when you come in ... Try not to make too much noise because of the neighbours. They're not angry people, they're nice people, but it's just so we don't disturb them (Felix at 10)

Conversely, unwanted noise was perceived as anti-social, a means through which to avoid social interaction. Louise viewed her oldest brother as wanting to cut himself off from the rest of the household, through the music blaring from his bedroom. Similarly, JazzyB (at 14) was intensely aware of how being 'loud' might be judged in her (new) local area:

I think if we're loud then I think they will think that we're naughty but if we're quiet I think they will think we are all good children.

However, the SAF data also enabled the author to identify and re-think her assumptions around other aspects of belonging in 'ordinary' family contexts. In particular, while most SAF respondents did not question that they belonged where they lived, this work highlighted considerable ambivalence towards and conflict within home spaces, and identified how belonging might be attached to a range of objects and spaces both within and beyond a conventional, singular home space.

SAF participants' ambivalence as regards home spaces often related to their lived experience of the size, repair and location of their homes, parent-child power relationships, the transient nature of young people's expected presence in the home, and the demands of school and of the economy. In some cases concurrent understandings of the home as a 'haven' but also as an economic asset which might need to be sold, and as a place parents also work became clear. As Alannah (17) pointed out in relation to the 'living room':

It aint' really a family area this room because my mum is usually working.

Such pressures resulted in everyday conflict between family members around the limited space and resources available. In contrast to idealised portrayals of family life, those happiest with their homes were often the minority who could retire to bedrooms (or sheds) they did not have to share to watch TV or play computer games. For example, Ash was particularly fortunate in that there was a shed containing a drumkit, sound system, sofa and blinds at the bottom of the garden of his parents' small suburban, terraced house (also visible in the photos):

so if I want my own space from my mum and dad, where sometimes I can do things that I'm not allowed to do in the house ...then l'll go down there for my own time.

Many respondents felt pushed out of common areas especially in the evenings and at other times too, if parents worked from home, as in Alannah's case, or did not work. Most respondents also had to share a bedroom at some point, while others had to store things in siblings' rooms because of a lack of space. Often these situations led to arguments with parents stepping in to try to resolve them (Gillies and Lucey 2006; Lucey 2013). For example: 
most of my toys and stuff are in his bedroom because [mine] is really small, and he goes 'Hurry up! You've got ten seconds ... And I hope you don't mind me saying this, but, if I take too long, then ..he might push me a bit, and he might shove me.... Well my mum ... starts shouting. And my dad starts shouting [in deeper voice]. 'He can go into the room whenever... he can play the play station whenever he wants!' (Ash at 9, prior to the shed).

Holly (at 13) complained about sharing a room with her younger sister, the lack of privacy and unwanted noise this entailed, and the resultant pillow fights:

the fact that we share a room just adds to the way that she can annoy me. Like ..she'll still be up when I get into bed and then she'll start singing [said with vehement frustration] and it gets really irritating. Last night we had a pillow fight, whacking each other...

Varying degrees of violence between siblings seemed to be somewhat, if not quite, normalised therefore. For example, Izzy (at 15) coyly distinguished the level of violence involved in her scraps with her sister from those of her friends:

I've never been in a violent argument. Well me and my sister will probably thump each other on the leg or shove each other but I would never punch her hard in the face... like some of my friends.

Meanwhile, Lizzie (at 11) distanced herself, but not her sister, from the use of considerable force:

And sometimes she starts pulling my hair and biting and hitting me and kicking me.

The conflicts and the lack of privacy highlighted by many respondents, and the potentially temporary nature of their status within the 'family home', further influenced their sense of belonging in particular spaces at different times, and the range of spaces in which they felt they belonged. Further, this experience seemed to shape a different aesthetic of space and belonging to that of adult family members, often focused on small, personalised spaces or particular objects. For example, since many respondents did not have their own rooms, concerns for privacy and personalisation were focused on smaller spaces such as a bed, or on an object such as the private box also mentioned by Allie (at 9):

INT: $\quad$ And in your bedroom have you got a space that's a more private space [that older sister] isn't allowed to go into?

ALLIE: My bed, my desk. I have this box that says [name] on it and my dad carved it and she's not allowed to go into that.

Maya (6), who shared a bedroom with two siblings, also identified a 'squashy' place that was particularly hers, at least while she was small enough to fit into it:

INT: $\quad$ So have you got any special place that's just yours and nobody else's..?

MAYA: Sometimes I go in there.

INT: In that cupboard?

MAYA: Yeah.

These accounts helped therefore to interrogate more idealised assumptions of family life within conventional home spaces pointing to an 'ordinary' desire for a degree of spatial autonomy from family, within a sense of belonging to it. Similarly, several respondents delighted in a kind of temporal autonomy at times of the day when other family members 
were out. Jay recounted standing in front of the big mirror in her mum's room; 'with my brush ...singing and acting like an idiot [laughs]'. For Malaky (at 11) too, the times she felt alone in the house were special:

In the morning I don't really see anyone cos it's after my dad has gone and before my brother is up ...I do love being in the house on my own.

In addition to identifying a concern for temporary and spatial autonomy within the home, the SAF analysis also suggested a different 'home' aesthetic to that of parents, reflecting the young people's relative lack of decision-making power there. For example, photos of bedrooms often focused on electrical, musical (computers, mobile phones, i-pods), and sporting equipment rather than representing any holistic or conventionally 'homely' sense of the room. On reflection, this 'smaller', and what seemed initially to be a cold, impersonal, focus may be related in part to the young people's lack of control over the decoration of their bedrooms. Holly, notably, complained about the 'irritating' purple colour on the walls of her room in each of her interviews. In her third interview she was excited as her room was to be repainted at last. It became clear however that this decision reflected her parents' decision to sell the house rather than her long-standing complaints.

At the same time, the importance of these electrical objects sometimes related to the young people's concern to gain some aesthetic control over their environment. For example, Richard's photos emphasised the computer and i-phone through which he could create his own world through listening to music:

INT: $\quad$ How important is it to you to have your own space at home?

RICHARD: Considerably I would say. Like moving in my own little world of music and stuff (at 18).

This analysis also helped to break down an implicit notion of belonging focused on a singular domestic space. For example, in addition to providing the possibility of aesthetic control, several of these items also related to the participants' contacts, interests and identities outside of the home. Unlike in the pictures of living rooms there were few family photos, but some of friends, alongside posters of sports teams and bands. Some of the electronic equipment was also used to maintain contacts outside of the home through social networking, texting or talking on the phone:

INT: How often do you use MSN then?

JAY: $\quad$ Every day [laughs] 1 or 2 hours per day (at 15).

As such the young people's aesthetics often highlighted connections beyond their homes and families. Such connections are often associated with young people's developing identities and independence. However, they may also reflect an appreciation that while their time living at home may be limited, these items were really 'theirs' and in some ways they thus provided a potentially more permanent sense of home or of 'belonging' in the sense of ownership.

Further, the SAF respondents' sense of 'belonging in or to' was not limited to one bricks and mortar space but often included friends' houses. Sometimes, as in the PSM studies, such arrangements related to difficult home circumstances. A friend of Jazzy's had spent some time living at her house after having been beaten up by her father. Allie, at 17 , spoke of having a sometimes better relationship with a friend's mother than with her own: 
She pays for a lot of things that my mum doesn't do so..and I feel like I can talk to [friend's] mum about anything really....but I wouldn't be able to tell my mum anything.

However, such arrangements did not always relate to more difficult home circumstances. Holly spoke of 'living' at a friend's house and laughed that this friend's mother referred to her as her 'other daughter'. At 14, Danielle spent a lot of time at the house of a friend whose family attended the same church and summer festivals:

I have my own bed at their house. It's an 'under-bed' but she can barely be bothered to put it away...practically always it's there and I leave clothes at their house and get clothes from her older sister and stuff.

By 16 she was spending even more time at this friend's place:

I get out of the house as much as possible now. I used to do it quite a lot when I was younger but like I can now leave pretty much and round to my friend's and spend a lot of time there.

This analysis had an important influence on the development of the SAS project. Notably, it reinforced the potential significance of objects. It further indicated that belonging should not only be explored with respect to conventional, or even exclusively indoors, places and that the aesthetic associated with these spaces might be significant. In addition, it prompted a more nuanced re-evaluation of the (even greater) time spent by many PSM respondents at friends' houses. The SAF analysis indicated that such practices were not exclusive to young people in more difficult circumstances, but commonplace. This insight therefore suggested their importance to the PSM respondents lay not only in having access to such alternative, safer, more 'home-like' places elsewhere in which to spend time generally associated with home life, but that these practices could be presented as 'normal'.

\section{Discussion}

The aim of this paper was to illustrate how QSA of archived data, much of which is relatively easily accessible online, can help researchers place their own research history, and the assumptions sedimented over its course, under scrutiny. The difficulties associated with the re-use of such data, and time investment required, must also be acknowledged, however. As Gillies and Edwards found: 'identifying and selecting transcripts is a labour-intensive, time-consuming process corresponding to the time and effort involved in primary data collection' (2005: para 24). In particular, this may be because an important aspect of 'finding' relevant project data relates to epistemological approaches. Gillies and Edwards' concern that information available about archived data, should 'illuminat[e] the very particular perspectives knowledge was (and is) created from' (2005; para 27) is therefore critical. At the same time, as Crow identifies in relation to working with re-studies, there may also be an 'inevitability of subjectivity' (2012: 407) to the way that certain projects (or questions) feel 'right' at a certain time.

The tasks of identifying a relevant project and of situating sample characteristics (crucial where the aim includes comparing 'ordinary' with less advantaged samples) might however be facilitated to some degree by the further development of archiving practices to include more contextual data. The current provision of relatively bare sociodemographic data, modelled on those required for the British Household Longitudinal 
Survey, would not seem sufficient to situate the backgrounds of participants. Here, further information on the type of tenure in which respondents live, the schools attended, parental occupations and changes in these over time had to be gleaned from detailed analysis of the individual interviews to situate the respondents' circumstances better. The importance of properly funding researchers to produce project guides, such as that created for the SAF project, which includes much useful information, and notably a detailed list of the methods employed, is therefore clear. However, this process could be taken further by providing a bibliography of the work that influenced project development and, as also recommended by Baker (2010), more on the disciplinary and research histories of all the original research team, pen portraits of respondents and detailed cross-interview tabulations of their socio-economic circumstances.

However, this paper has also illustrated how such QSA may produce important substantive and methodological insights. Notably, the potential of participatory, photographic methods, adding 'texture' (Rose 2007) to the respondents' discussions of particular spaces important to them was highlighted by this process. For example, certain photos reinforced a sense of material poverty suggested in some interviews, while others pointed to the frequently unequal distribution of household resources towards shared and more public rooms rather than teenagers' bedrooms. In addition, the way respondents' photos often focused on individual objects rather than their rooms in a more holistic sense further suggested not only their particular importance to the respondents, but also an aesthetic associated with the importance of communication outside of the home and ultimately a projected temporal limit to their residence there. Similarly, this analysis highlighted an ordinary ambivalence towards and need for temporal and spatial autonomy within domestic living spaces. Further, while the SAF photos were limited to the places in which the respondents officially lived, overall these interviews alerted the author to notions of home and belonging spread across various spaces, including friends' houses. Each of these insights was important to the subsequent development of the SAS project. For example, a decision was made not to limit any notion of belonging to one specific home, as conventionally defined, but to suggest that participants took photos of their favourite places, in which they felt 'at home', wherever that may be.

Elements of this analysis further identified and disturbed assumptions and conceptualisations built up over the course of the author's research career. Notably, this work raised difficult questions around the subtly divergent construction of, and research with 'ordinary' and 'vulnerable' samples of young people in different disciplinary locations and supported by different types of funders. Comparing the PSM and SAF interviews made several overlaps in members of these different samples' practices visible, for example in relation to their identification and use of 'home' spaces away from the place they lived, something the author had previously associated exclusively with more vulnerable young people. This work allowed therefore for a consequently more nuanced understanding of young people's strategies in difficult circumstances. Rather than suggesting that their practices were completely different to those of 'ordinary' young people and explicable only in relation to difficult social circumstances, this analysis suggested that the PSM respondents were drawing on and extending common practices of developing autonomy for their age group. These and other examples within the SAF data of 'ordinary' spatial and temporal conflicts, and of a common ambivalence towards the 'home', further suggest that the idealised 'safe haven' image of the happy family sharing one space and its resources (Gillis, 1996) remains to be fully deconstructed and understood in spatial and sensory terms. 
The further political dimension of making such overlaps in experience and the difficulties and conflicts within ordinary families visible, is also important. Currently, a much criticised but influential UK government rhetoric of 'troubled families' associates difficult social circumstances with causing trouble, or 'anti-social behaviour'. Like notions such as 'the underclass', such labels morally distance the practices of those figuratively identified by them from those characterised in the same rhetorics as 'decent' 'ordinary' 'hard-working families'. Such QSA therefore provides one means of shining a light on how such perceptions can slither into one's own research practice in different forms, as for example in the first PSM project's greater focus on respondents' risky behaviours than on their education. Equally, the lesser attention paid to difficult experiences within relatively 'ordinary' samples may be critiqued as cumulatively, implicitly reinforcing idealised notions of the 'family we live by' (Gillis 1996) that associate family conflict with 'troubled' rather than more 'ordinary' family circumstances. These findings illustrate the importance of Heaphy's concern that sociologists recognise how sociology itself is involved in strategies of power (2008: 5.3) and 'acknowledge[s] the partial narratives we tell about the lives we study, and the political consequences of these' (2008: 1.3). As discussed, in his view, a 'radical' or 'methodological' reflexivity is required in relation to all levels of data production including starting assumptions, sample construction, methods, interpretations and the identity of interpreters, in order that the procedures and assumptions underpinning 'sociological claims and interpretations' may be made more 'visible' (2008: 5.3). While, as Heaphy points out, such scrutiny can never be entirely objective, this type of QSA may be one way of attempting such reflexivity and of adopting the kind of 'investigative epistemology' required to keep a sociological imagination open.

\section{Acknowledgements}

I am very grateful to the SAF researchers and Timescapes archive for the very rich data from which I learnt so much and which contributed greatly to the development of the 'SAS' or Young People Creating Belonging: spaces, sounds and sights project, and to the ESRC for funding (RES-061-25-0501). The comments of the three anonymous reviewers of this paper were also very helpful in improving this paper.

\section{References}

BAKER, S (2010) Reflections on Secondary Analysis of the 'Siblings and Friends' Data http://www.timescapes.leeds.ac.uk/assets/files/Project\%201\%20Secondary\%20Analysis \%20Pilot.pdf (accessed 30 March 2014).

BANCROFT, A, Wilson, S, Cunningham-Burley, S, Backett-Milburn, $\mathrm{K}$ and Masters, $\mathrm{H}$ (2004) Parental Drug and Alcohol Misuse: Resilience and Transition among Young People. York: Joseph Rowntree Foundation.

BURAWOY, M (2009) The Extended Case Method: Four Countries, Four Decades, Four Great Transformations and One Theoretical Tradition. Berkeley: University of California Press.

CROW, G (2012) 'Community re-studies: lessons and prospects', The Sociological Review Vol. 60., p.405-420.

DENORA, T (2000) Music in Everyday Life. Cambridge: Cambridge University Press. GEIGER, T, Moore, N and Savage, M (2010) The Archive in Question (ESRC National Centre for Research Methods Review Paper). National Centre for Research Methods NCRM/016. 
GILLIES, V (2000) 'Young people and family life: analysing and comparing disciplinary discourses', Journal of Youth Studies Vol.3. No. 2, p. 211-228.

GILLIES, V and Edwards, R (2005) 'Secondary analysis in exploring family and social change: addressing the issue of context', Forum: Qualitative Social Research Vol. 6, No. 1: art 44.

GILLIES, V and Lucey, $\mathrm{H}$ (2006) 'It's a connection you can't get away from': brothers, sisters and social capital', Journal of Youth Studies Vol. 9, No. 4, p. 479-493.

GILLIS, J (1996) A World of their Own Making. A History of Myth and Ritual in Family Life. Oxford: Oxford University Press.

HEAPHY, B (2008) 'The sociology of lesbian and gay reflexivity or reflexive sociology', Sociological Research Online Vol. 13, No. 1: www.socresonline.org.uk/13/1/9.html. HOUMØLLER, K, Bernays, S, Wilson, S and Rhodes, T (2011) Juggling Harms: Coping with parental substance misuse. London: School of Hygiene and Tropical Medicine/ Department of Health.

IRWIN, S and Winterton, M (2011) Timescapes Data and Secondary Analysis: Working Across the Projects (Timescapes Working Paper No. 5). Leeds: Timescapes. IRWIN, S and Winterton, M (2012) 'Qualitative secondary analysis and social explanation', Sociological Research Online Vol. 17, No. 2:

http://www.socresonline.org.uk/17/2/4.html

IRWIN, S, Bornat, J and Winterton, M (2012) 'Timescapes secondary analysis: comparison, context and working across data sets', Qualitative Research Vol. 12, No. 1, p. 66-80.

LUCEY, H (2013) The trouble with siblings: some psychosocial thoughts about sisters, aggression and femininity in Ribbens McCarthy, J, Hooper, C-A, and Gillies, V (eds.)

Family Troubles: Exploring Changes and challenges in the Family Lives of Children and Young Children, Bristol: The Policy Press, p. 173-184.

MASON, J (2007) 'Re-using qualitative data: on the merits of an investigative epistemology', Sociological Research Online Vol. 12, No. 3:

http://www.socresonline.org.uk/12/3/3.html.

MASON, J and Tipper, B (2008) 'Being related: how children create and define kinship', Childhood Vol. 15, No. 4, p. 441-460.

MASON, J and Davies, K (2010) 'Coming to our senses? A critical approach to sensory methodology', Qualitative Research Vol. 9, No. 5, p. 587-603.

MAUTHNER, N, Parry, O and Backett-Milburn, K (1998) "The data are out there or are they?': implications for archiving and revisiting qualitative data', Sociology Vol. 32, No. 4, p. $733-745$.

MILLER, D (2010) Stuff. Cambridge: Polity Press.

PINK, S (2009) Doing Sensory Ethnography. London: Sage.

ROSE, G (2007) Visual Methodologies. 2nd ed. London: Sage.

WELLER, S and Edwards, R with Stephenson, R (2011) Timescapes: Your space!

Siblings and Friends Project Guide. Leeds: Timescapes.

WILSON, S, Houmøller, K, Bernays, S (2012) "It just feels nice to go home to a nice home, and not, some house': Taking account of the sensory construction of difficult family relationships in domestic spaces', Children's Geographies Vol. 10, No. 1, p. 95-107. WILSON, S (2013) Thinking about sociological work on personal and family life in the light of research on young people's experience of parental substance misuse in Ribbens McCarthy, J, Hooper, C-A, and Gillies, V Family Troubles: Exploring Changes and Challenges in the Family Lives of Children and Young Children. Bristol: The Policy Press, p. 163-172. 
WINTERTON, M, Crow, G and Morgan-Brett, B (2011) Young Lives and Imagined

Futures: Insights from Archived Data. (Timescapes Working Paper Series No. 6). Leeds:

Timscapes.

\footnotetext{
${ }^{\mathrm{i}}$ The SAF study draws on samples of children and young people from three previous projects conducted by the Families and Social Capital Research Group at London South Bank University between 2002-2005. Participants aged 5-13 at the time of the original interviews from all three studies were invited to take part in two waves of follow up work focused on their lateral relationships. The resultant data set is one of the original seven Timescapes projects www.timescapes.leeds.ac.uk (ESRC RES 347-25-0003) which ran from 2007-2011.

ii This data is available in the UK Data Archive (www.data-archive.ac.uk) to users in any country. iii This project was supported by the ESRC (RES-061-25-0501). Further details may be found here: www.research-unbound.org.uk<http://www.research-unbound.org.uk

iv 'Looked after' children designates those in the care of the state, often living in kinship, foster, residential or secure care. In Scotland, the term may include children living with their parents but under social work supervision.

${ }^{v}$ The pseudonyms used in this paper are those employed in the SAF data.

${ }^{v i}$ The SAF data employs particular codes to refer to such anonymised information. These have been simplified to square brackets in this paper.
} 